\title{
Venture capital e private equity no Brasil: alternativa de financiamento para empresas de base tecnológica
}

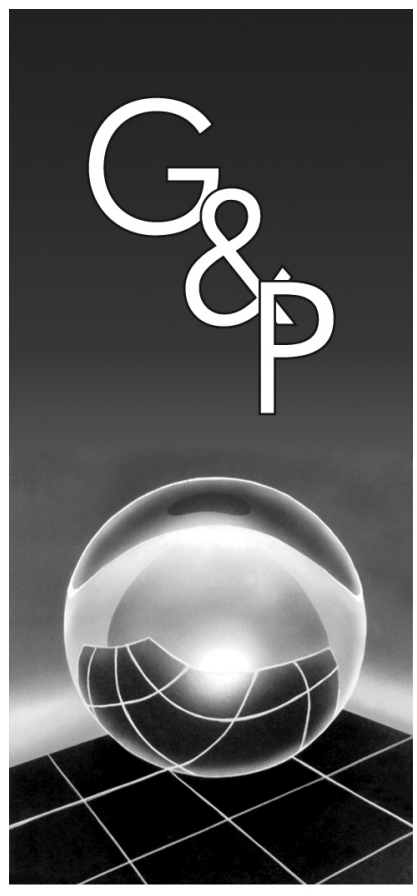

Jorge Luís Faria Meirelles

Tabajara Pimenta Júnior

Daisy Aparecida do Nascimento Rebelatto

\section{Resumo}

Este texto tem como objetivo analisar o setor brasileiro de venture capital e private equity (VC/PE), buscando apresentar, com base na literatura e em fontes secundárias de dados, as suas principais características e tendências, assim como a sua potencialidade como alternativa de financiamento para as empresas em geral $e$, sobretudo, para as empresas de base tecnológica. O trabalho apresenta, também com base na literatura, as mudanças na legislação e as principais iniciativas governamentais para o desenvolvimento do setor de VC/PE, no Brasil.

Palavras-chave: Venture capital. Private equity. Capital de risco. Financiamento. Tecnologia.

\section{Introdução}

As exportações brasileiras são fortemente concentradas em commodities primárias, que representam cerca de $40 \%$ do total. A composição da pauta de exportação brasileira é significativamente diferente da composição da pauta das exportações mundiais, em que a participação das commodities é de apenas $13 \%$. A possibilidade de ampliar a inserção do Brasil nos mercados de maior conteúdo tecnológico e, conseqüentemente, de maior valor agregado, é uma questão especialmente relevante (DE NEGRI et al. 2005).

Vários autores destacam a importância do investimento em inovação tecnológica, uma vez que a melhoria do nível tecnológico é um aspecto fundamental para a criação de vantagens competitivas sustentáveis (NELSON; WINTER, 1982; DOSI, 1988; FREEMAN, 1982) e para o crescimento econômico a longo prazo (FAGERBERG, 1994). A competitividade de uma nação depende da capacidade de sua indústria para inovar, um aspecto que se forma pouco a pouco (HEIJS, 2001).

Uma das condições necessárias ao desenvolvimento de novas tecnologias é a possibilidade de financiamento. No entanto, segundo Nascimento (2004), as restrições ao financiamento das empresas, no Brasil, constituem um fato empírico evidente, não apenas no que se refere ao acesso ao crédito, mas, sobretudo, com relação aos prazos curtos e ao custo do financiamento, reconhecidamente um dos maiores do mundo.

O saldo dos empréstimos no sistema financeiro brasileiro atingiu $\mathrm{R} \$ 841,5$ bilhões, em agosto de 2007, representando $33 \%$ do PIB - produto interno bruto (BACEN, 2007). A média da intermediação financeira dos países da OCDE (Organização para a Cooperação Econômica e Desenvolvimento) é de 76\% do PIB. Mesmo os países em desenvolvimento apresentam uma média de 58\% do PIB (BECK; LEVINE, 2000).

Se, no Brasil, a obtenção de financiamento para a realização de investimentos em geral é algo difícil, os financiamentos para o desenvolvimento de novas tecnologias são ainda mais escassos. Tal escassez é enfrentada pelas empresas de base tecnológica (EBTs).

Diferentemente das empresas de setores tradicionais, que utilizam em seu processo produtivo tecnologias maduras, as EBTs são organizações que fundamentam suas atividades produtivas no desenvolvimento de novos produtos ou processos, com base na aplicação sistemática de conhecimentos científicos e tecnológicos e utilização de técnicas avançadas ou pioneiras (FINEP, 2007). 
O problema da falta de crédito junto a instituições financeiras ou investidores diretos já foi apontado como uma das maiores dificuldades ao desenvolvimento de EBTs. O risco associado às fases iniciais de desenvolvimento das tecnologias e produtos adotados por essas empresas é o fator que inibe a concessão de crédito por parte das instituições financeiras que lidam com financiamentos tradicionais (SEBRAE, 2001).

Do ponto de vista dos credores, as incertezas associadas ao desenvolvimento e implementação de novos produtos ou processos são traduzidas na maior imprevisibilidade das projeções de fluxos de caixa das empresas que desejam obter financiamento. Além disso, quanto menores forem as garantias reais oferecidas pelas EBTs (o que é comum no caso de empresas pequenas e em estágios iniciais de desenvolvimento), menores são as chances de concessão de crédito por parte das instituições financeiras.

Christensen (1992) destaca que investimentos em inovação tecnológica implicam em maiores incertezas, quando comparados aos demais tipos de investimento. Além da incerteza de mercado, associada ao sucesso ou insucesso de uma inovação (processo de seleção pelo mercado), há a incerteza técnica, relacionada ao risco técnico de desenvolvimento de novos processos ou produtos.

A implementação de inovações tecnológicas está associada ao desenvolvimento de diferentes atividades inovativas, como pesquisa básica ou aquisição de máquinas e equipamentos para a implementação de produtos ou processos novos ou tecnologicamente aperfeiçoados. Cada atividade inovativa apresenta um nível diferente de incerteza.

Freeman (1982) divide a incerteza em vários níveis, associados aos diferentes tipos de atividade inovativa. Estes níveis de incerteza, em ordem decrescente, vão da pesquisa básica até a realização de pequenos melhoramentos técnicos, como mostra o Quadro 1.

Embora apresente intensidades diferentes, a incerteza é um dos principais elementos relacionados às atividades inovativas, que possuem, por este motivo, algumas peculiaridades. Uma delas refere-se às suas possibilidades de financiamento. Freeman (1982) observa que, mesmo no caso das inovações com níveis de incerteza mais baixos, apenas uma pequena proporção delas é financiada por meio de captação de recursos no mercado financeiro. A forma mais comum de financiamento do processo inovativo é a utilização de recursos próprios.

Contudo, para a produção de um novo produto em escala de mercado, ou a implantação de um novo processo, a empresa tem que realizar investimentos para os quais ela geralmente não possui disponibilidades financeiras imediatas.
Quadro 1. Diferentes níveis de incerteza das atividades inovativas. Fonte: Freeman (1982).

\begin{tabular}{ll}
\hline Incerteza real & $\begin{array}{l}\text { Invenção fundamental; e } \\
\text { pesquisa básica }\end{array}$ \\
\hline Incerteza muito alta & $\begin{array}{l}\text { Inovações de produto e de processo } \\
\text { radicais realizadas fora da empresa }\end{array}$ \\
\hline Incerteza alta & $\begin{array}{l}\text { Inovações de produto relevantes; e } \\
\text { inovações de processo radicais na pró- } \\
\text { pria empresa }\end{array}$ \\
\hline Incerteza moderada & Novas gerações de produtos existentes \\
\hline Incerteza baixa & $\begin{array}{l}\text { Inovações licenciadas; } \\
\text { imitação de inovações de produto; } \\
\text { modificações de produto ou processo; e } \\
\text { adoção precoce de processos já existen- } \\
\text { tes }\end{array}$ \\
\hline Incerteza muito baixa & $\begin{array}{l}\text { Novo modelo; } \\
\text { diferenciação de produto; } \\
\text { implementação de nova função para } \\
\text { produto já existente; } \\
\text { adoção tardia de inovações de processo } \\
\text { já existentes; e } \\
\text { pequenos melhoramentos técnicos }\end{array}$ \\
\hline
\end{tabular}

Uma alternativa de financiamento para as empresas em geral e, sobretudo, para as EBTs, consiste no aporte de capital do tipo venture capital ou private equity (VC/PE). A experiência internacional mostra que esta é uma das formas de alavancar a participação privada no conjunto dos gastos em ciência e tecnologia, já tradicional nos EUA, mas que vem crescendo acentuadamente nos últimos anos nos países europeus e em algumas economias emergentes. Dentre outras iniciativas, os fundos de VC/PE foram objeto de estímulo em vários países, na medida em que são percebidos como um dos mecanismos mais diretos e eficientes de aproximação entre os investidores e os projetos/empresas de base tecnológica, que podem beneficiar-se dos recursos e da experiência gerencial trazida pelos gestores dos fundos (CGEE, 2003a).

Nesse contexto, o presente trabalho tem como objetivo analisar o setor brasileiro de VC/PE, buscando apresentar, com base na literatura e em fontes secundárias de dados, as suas principais características e tendências, bem como identificar seu potencial como alternativa de financiamento para as empresas em geral e, sobretudo, para as empresas de base tecnológica. O trabalho apresenta, também com base na literatura, as mudanças na legislação e as principais iniciativas governamentais para o desenvolvimento do setor de VC/PE, no Brasil.

Os números sobre o setor brasileiro de $\mathrm{VC} / \mathrm{PE}$, aqui apresentados, estão baseados fundamentalmente no trabalho de Ribeiro (2005) e na pesquisa de Carvalho; Ribeiro e Furtado (2006), do Centro de Estudos sobre PE e VC (CEPE), da Fundação Getúlio Vargas (FGV), referentes a dezembro de 2004. 


\section{2 venture capital e private equity: aspectos conceituais e principais características}

Venture capital e private equity (VC/PE) são segmentos do mercado financeiro que consistem fundamentalmente em aporte temporário de capital, realizado por um fundo de $\mathrm{VC} / \mathrm{PE}$, por meio de participação no capital de empresas com potencial de crescimento e expectativa de grande valorização. A valorização da empresa permitirá ao fundo de VC/PE obter retorno com a venda da participação (desinvestimento) a médio ou longo prazo.

O que torna venture capital (VC) uma classe de investimento diferente de private equity (PE) é o estágio de desenvolvimento das empresas que recebem o aporte de capital. Os investimentos do tipo VC são direcionados para empresas em estágios iniciais de seu desenvolvimento, além de apresentarem uma participação mais ativa dos gestores do fundo de VC nas empresas investidas (RIBEIRO, 2005). Já o termo private equity é comumente utilizado como sinônimo de investimentos em empresas amadurecidas, sem que isso necessariamente implique em menor envolvimento do gestor (CARVALHO et al., 2006).

A expressão venture capital, da língua inglesa, é na maioria das vezes traduzida para a língua portuguesa como capital de risco. Outra tradução utilizada é capital empreendedor.

Segundo Carvalho et al. (2006), os estágios de desenvolvimento das empresas que recebem aporte de capital do tipo venture capital são: (i) capital semente (seed capital): geralmente representa um pequeno aporte, feito em fase pré-operacional, para o desenvolvimento de um produto, ou ainda para testes de mercado ou registro de patentes; (ii) estruturação inicial (start-up): aporte de capital para empresa em fase de estruturação, em geral no primeiro ano de seu funcionamento, quando ainda não vende seus produtos/serviços comercialmente; e (iii) expansão: aporte de capital para a expansão das atividades de uma empresa que já vende seus produtos comercialmente.

Para Carvalho et al. (2006), os estágios de desenvolvimento das empresas que recebem aporte de capital do tipo private equity são: (i) estágios avançados (late stage): aporte de capital em empresas que já atingiram uma taxa de crescimento relativamente estável e já apresentam fluxo de caixa positivo; (ii) financiamento de aquisições (aquisition finance): capital para expansão por meio de aquisição de outras empresas; (iii) tomada de controle pelos executivos (MBO/I - management buyout/ in): capital para financiar a equipe de gestores, da própria empresa ou externos, que objetivam adquirir o controle de uma empresa; (iv) estágio pré-emissão (bridge finance): aporte feito quando a empresa planeja uma introdução em bolsa de valores em um prazo de até dois anos; (v) recuperação empresarial (turnaround): aporte feito quando a empresa encontra-se em dificuldade operacional e/ou financeira e há expectativa de recuperação; (vi) mezanino: investimentos em estágios avançados do desenvolvimento da empresa, realizados por meio de dívidas subordinadas; e (vii) PIPE (private investment in public equity): é um estágio à parte que representa a aquisição do capital acionário de empresas já listadas em bolsa de valores.

É importante destacar que a definição dos estágios empresariais e sua classificação como VC ou PE é arbitrária. Alguns autores preferem incluir expansão entre os estágios de PE, bem como classificar capital semente como uma categoria em si (CARVALHO et al., 2006). Outros autores preferem classificar mezanino como uma categoria à parte.

Os principais participantes da atividade de VC/PE são os investidores, as organizações gestoras, os veículos de investimento (fundos de $\mathrm{VC} / \mathrm{PE}$ ) e as empresas investidas, como mostra a Figura 1.

Os investidores aplicam seus recursos em fundos de VC/PE, os quais são administrados por uma companhia de VC/PE (organização gestora). Com os recursos aplicados nos fundos de VC/PE, são realizados aportes de capital em empresas selecionadas (empresas investidas). Tal aporte de capital ocorre por intermédio de participação acionária, ou outros instrumentos, como dívidas conversíveis em ações e bônus de subscrição.

Segundo Gompers (1995), o papel dos gestores de fundos de VC/PE não é somente aportar capital, mas também reduzir o risco dos empreendimentos, propiciando, desta forma, uma maior probabilidade de sucesso destes. Isto ocorre porque, enquanto o empreendedor está mais voltado às questões técnicas e de produção, o investidor contribui significativamente com sugestões e propostas em relação ao gerenciamento da empresa.

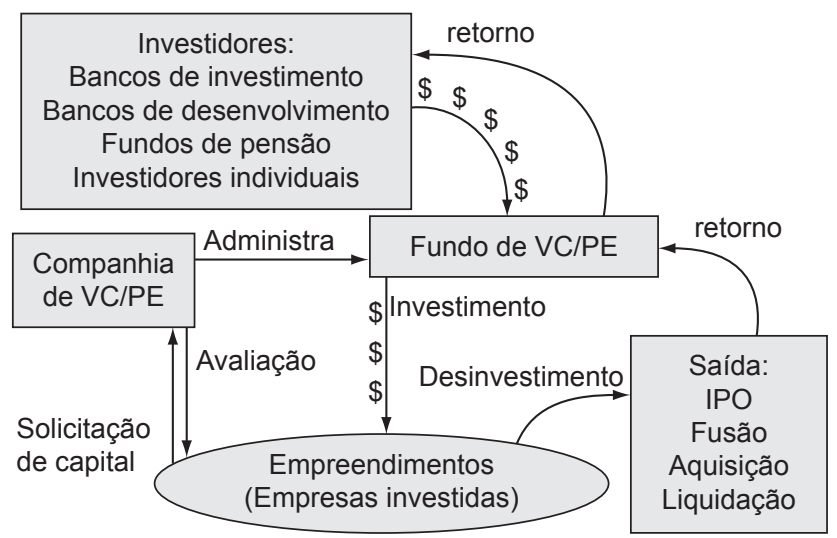

Figura 1. Principais participantes da atividade de VC/PE. Fonte: Adaptado de Ganzi et al. (1998). 
Os gestores de fundos propiciam a profissionalização da gestão do negócio, ampliação da rede de relacionamentos, práticas de governança corporativa, possibilidade de ganhos de escala, abertura de canais de crédito e aproveitamento de atividades complementares de outras empresas que receberam aporte de capital do fundo. Esta atuação tem como resultado a redução do risco de cada negócio financiado.

Após determinado período de aporte de capital, ocorre o desinvestimento, que representa a saída do fundo de VC/PE da participação na empresa investida. Essa saída pode ocorrer, dentre outras maneiras, por meio da venda da empresa a um grupo empresarial ou abertura de capital - realização de oferta pública inicial (IPO), na bolsa de valores. O retorno do investidor depende da valorização da empresa investida.

Do ponto de vista da empresa investida, o aporte de capital do tipo VC/PE consiste em um financiamento de longo prazo, em que não são exigidas garantias e não há periodicamente o pagamento de juros ou a amortização do principal, como ocorre nos financiamentos tradicionais, o que dificultaria o reinvestimento do caixa gerado pela empresa.

Já do ponto de vista do investidor, o investimento em VC/PE apresenta baixa liquidez e há o risco da empresa que recebeu aporte de capital não se valorizar como o esperado. Para que esse risco seja reduzido, os gestores de fundos de VC/PE realizam um criterioso processo de análise das empresas, antes de realizarem os aportes de capital. Após a escolha criteriosa, os gestores também minimizam o risco ao acompanhar as empresas investidas, dando-lhes suporte gerencial. Além disso, os gestores realizam aporte de capital em várias empresas, de tal maneira que ocorra a diversificação do investimento, o que possibilita que o fracasso de uma empresa seja compensado pela grande valorização de outra.

\section{Setor brasileiro de VC/PE}

A atividade de VC/PE surgiu nos EUA e sua difusão para os demais países envolveu a reprodução adaptada do modelo estadunidense, com políticas e ações específicas à realidade de cada país (NASCIMENTO, 2006).

$\mathrm{O}$ setor de $\mathrm{VC} / \mathrm{PE}$ no Brasil é muito recente. A experiência do BNDES começou em 1974, com a criação de três subsidiárias voltadas para esta atividade, que seriam fundidas em 1982, sob o nome BNDESPAR.

A primeira gestora privada de VC/PE do Brasil foi a Brasilpar, criada em 1976. Entre 1981 e 1993 surgiram seis organizações de $\mathrm{VC} / \mathrm{PE}$, mas o grande ciclo deste setor, no Brasil, iniciou-se após a estabilização monetária, com forte expansão no período 1999-2001. O pico ocorreu em 2000, quando 13 organizações entraram no mercado (RIBEIRO, 2005).
Segundo Ribeiro (2005), existiam no Brasil, em 2004, 65 organizações de VC/PE. Foram consideradas organizações tanto nacionais quanto internacionais, desde que estas tivessem escritórios no Brasil.

Havia também seis organizações especializadas em fundos do tipo PIPE. Estas organizações administravam sete fundos do tipo PIPE. Tais fundos tinham realizado aporte de capital em 43 empresas (CARVALHO et al., 2006).

De acordo com Ribeiro (2005), o capital comprometido pelo setor brasileiro de VC/PE, em dezembro de 2004 , era de US\$ 5,07 bilhões (equivalente a $0,84 \%$ do PIB brasileiro). Quando são considerados também os fundos do tipo PIPE, como faz Carvalho et al. (2006), o capital comprometido sobe para US\$ 5,58 bilhões, ao final de 2004.

Pesquisa realizada pelo Centro de Estudos em PE e VC, da FGV, em conjunto com o Instituto Endeavor, mostrou que o capital comprometido pelos fundos de VC/PE e PIPE atingiu US\$16,7 bilhões, em julho de 2007. Assim, o capital comprometido pelo setor brasileiro de VC/PE/ PIPE triplicou entre dezembro de 2004 e julho de 2007. Nesse período, surgiram 18 novas organizações gestoras de VC/PE/PIPE (VALOR FINANCEIRO, 2007).

No que se refere às organizações típicas de VC/PE, atuantes no Brasil em 2004, a maioria era nacional (72\% do total) e administravam $60 \%$ do capital comprometido. Já as originárias dos EUA representavam 15\% do total de organizações e administravam 35\% do capital comprometido. Do restante, quatro empresas tinham como origem a Europa (Espanha, Holanda, Inglaterra e Suíça) e quatro empresas outros países, como Chile, Ilhas Cayman e Ilhas Virgens Britânicas (RIBEIRO, 2005).

Alguns paraísos fiscais têm sido utilizados por gestores de $\mathrm{VC} / \mathrm{PE}$ para serem sede dos fundos. Isso ocorre devido às vantagens tributárias, simplicidade burocrática, confidencialidade e sistema jurídico favorável à solução de conflitos. Assim, embora $62 \%$ dos fundos fossem sediados no Brasil, mais da metade do capital comprometido no setor brasileiro de VC/PE era congregado por 13 fundos (12 LPs e uma holding), sediados nas Ilhas Cayman, como mostra a Tabela 1.

Tabela 1. País de constituição dos fundos de VC/PE. Fonte: Ribeiro (2005).

\begin{tabular}{lcc}
\hline País de constituição & $\begin{array}{c}\mathbf{N}^{\circ} \text { de fundos } \\
\text { de VC/PE }\end{array}$ & $\begin{array}{c}\text { Comprometimentos } \\
\text { (bilhões de US\$) }\end{array}$ \\
\hline Brasil & $56(62,3 \%)$ & $1,6(31,6 \%)$ \\
Ilhas Cayman & $13(14,4 \%)$ & $2,65(52,3 \%)$ \\
Estados Unidos & $9(10 \%)$ & $0,34(6,7 \%)$ \\
Outros países & $8(8,9 \%)$ & $0,36(7,1 \%)$ \\
Não especificado & $4(4,4 \%)$ & $0,12(2,3 \%)$ \\
Total & $90(100 \%)$ & $5,07(100 \%)$ \\
\hline
\end{tabular}


O tamanho médio dos fundos de VC/PE brasileiros, sediados nas Ilhas Cayman, era de US\$ 204 milhões. Já os fundos sediados no Brasil possuíam, em média, US\$ 38 milhões (RIBEIRO, 2005).

A maioria dos fundos de VC/PE brasileiros possui duração determinada. Os prazos mais comuns estão entre sete e dez anos, com possibilidade de extensão por mais dois anos (RIBEIRO, 2005). Segundo Megginson (2004), os prazos de duração dos fundos de VC/PE, nos EUA, têm variado entre sete e dez anos, podendo chegar a 15 anos.

De acordo com Sahlman (1990), o prazo de duração do fundo de VC/PE é a principal ferramenta de alinhamento de interesses entre o gestor do fundo e o investidor. Além de indicar ao gestor um prazo para a realização das saídas, mostra ao investidor o prazo de resgate do investimento, possibilitando a recusa da realização de um novo comprometimento de recursos. Dessa forma, o prazo determinado de duração do fundo possui importante função de governança.

Em Ribeiro (2005), só foi possível identificar a categoria do investidor para $80 \%$ dos US\$ 5,07 bilhões de capital comprometido no setor brasileiro de VC/PE, em 2004. Isso ocorreu porque alguns gestores estavam impedidos, por contrato, de divulgar informações sobre seus investidores.

Os principais investidores dos fundos de VC/PE no Brasil eram os fundos de pensão, os grupos empresariais e os bancos, como mostra a Tabela 2.

Embora os maiores investidores em fundos de VC/ $\mathrm{PE}$, tanto no Brasil como nos EUA, sejam os fundos de pensão, eles ainda possuem participação bem menor no setor brasileiro. Os fundos de pensão brasileiros possuem entre $0,3 \%$ e $0,5 \%$ do patrimônio de $\mathrm{R} \$ 340$ bilhões investidos em VC/PE. Nos Estados Unidos, esse índice varia entre 5 e $6 \%$ do patrimônio de US\$ 6 trilhões das fundações (FINEP, 2007).

$\mathrm{Na}$ Europa, segundo Megginson (2004), mais da metade do capital tem origem em bancos, seguradoras e agências do governo. Em 2002, dos 27,5 bilhões de euros levantados, os fundos de pensão haviam contribuído com $16,3 \%$ e o governo com $11 \%$.

Outro ponto que merece destaque é a participação de investidores estrangeiros no setor brasileiro de VC/PE, que representava $70 \%$ de todos os recursos comprometidos e, para algumas categorias de investidores, atingia 100\%. Já nos EUA, em 1999, apenas 20\% dos recursos eram de investidores estrangeiros (MEGGINSON, 2004).

As 65 organizações típicas de $\mathrm{VC} / \mathrm{PE}$, atuantes em 2004, administravam 90 veículos de investimento, sendo que 13 ainda não haviam iniciado seu ciclo de investimento e 77 haviam realizado aporte de capital em 263 empresas distintas.

Uma vez que algumas empresas receberam aporte de capital de mais de um veículo de VC/PE, essas 263 empresas correspondiam a um total de 315 investimentos. Na Europa, segundo Bottazzi et al. (2004), quase metade dos investimentos é realizada de maneira sindicalizada (que envolve duas ou mais organizações), o que indica que há menor cooperação entre as organizações atuantes no setor brasileiro de VC/PE.

A maioria dessas 263 empresas recebeu aporte de capital típico de venture capital, como mostra a Tabela 3.

No Brasil, enquanto a maioria das empresas que receberam aporte de capital do tipo venture capital estava em fase de expansão, na Europa, segundo Bottazzi et al. (2004), a maioria estava na fase de start-up e o financiamento do tipo seed capital era mais expressivo. Esses

Tabela 2. Principais investidores de VC/PE. Fonte: Ribeiro (2005).

\begin{tabular}{lccc}
\hline \multicolumn{1}{c}{ Classe } & $\begin{array}{c}\text { Comprometimentos } \\
\text { (milhões de US\$) }\end{array}$ & Porcentagem válida & Origem estrangeira (\%) \\
\hline Fundos de pensão & 686 & 17,2 & 24 \\
Empresas privadas & 634 & 15,9 & 43 \\
Bancos & 413 & 10,4 & 78 \\
Fundos de investimento & 362 & 9,1 & 94 \\
Trusts e Endowments & 353 & 8,9 & 100 \\
Pessoas físicas externas à organização & 334 & 8,4 & 82 \\
Outras organizações de VC/PE & 291 & 7,3 & 96 \\
Seguradoras & 290 & 7,3 & 99 \\
Governo e empresas públicas & 255 & 6,4 & 0 \\
Sócios da organização gestora & 198 & 5,0 & 48 \\
Instituições multilaterais & 131 & 3,3 & 100 \\
Organizações não governamentais & 41 & 1,0 & 100 \\
Não informado & 1.080 & - & 91 \\
Total & 5.068 & 100 & 70 \\
\hline
\end{tabular}


Tabela 3. Estágio de desenvolvimento das empresas investidas. Fonte: Carvalho, Ribeiro e Furtado (2006).

\begin{tabular}{lcc}
\hline \multicolumn{1}{c}{ Estágio das empresas } & $\mathbf{N}^{\circ}$ & $\%$ \\
\hline Capital semente (seed capital) & 36 & 13,7 \\
Estruturação inicial (start-up) & 72 & 27,4 \\
Expansão & 96 & 36,5 \\
Venture capital & 204 & 77,6 \\
Estágio avançado & 42 & 16,0 \\
Financiamento para aquisição & 5 & 1,9 \\
Tomada de controle pelos executivos & 3 & 1,1 \\
Capital pré-emissão (bridge finance) & 1 & 0,4 \\
Recuperação empresarial (turnaround) & 6 & 2,3 \\
Mezanino & 2 & 0,8 \\
Private equity & 59 & 22,4 \\
Total & 263 & 100 \\
\hline
\end{tabular}

dados mostram que os aportes de capital realizados no Brasil concentram-se em estágios mais avançados de desenvolvimento das empresas, em comparação aos dados europeus. Já nos EUA, de acordo com a NVCA (2005), a maioria dos aportes de capital é realizada no estágio de start-up, seguida pela fase de expansão e seed capital.

Dados de diversos países mostram que parte relevante dos investimentos realizados por organizações de $\mathrm{VC} / \mathrm{PE}$ está voltada para os setores de alta tecnologia, uma vez que estes setores podem proporcionar retornos maiores, por vezes astronômicos. Dados da OECD (2005) mostram que em 19, dentre 29 países analisados, durante o período 1998-2002, mais de 40\% dos investimentos foram direcionados para os setores de tecnologia da informação, telecomunicações, biotecnologia e saúde.

Dentre as 263 empresas que receberam aporte de capital do tipo VC/PE, no Brasil, destacam-se as EBTs, justamente as que realizam de maneira mais vigorosa o desenvolvimento de inovações tecnológicas. Do total, 91 empresas $(34 \%)$ eram do setor de informática e eletrônica e $29(11 \%)$ do setor de telecomunicações. Ainda no setor de tecnologia, destacam-se dez empresas de biotecnologia. Segundo Ribeiro (2005), mesmo nos setores tradicionais, parte das empresas que receberam aporte de capital eram intensivas em inovação.

Para que as organizações de VC/PE possam obter retorno em seus investimentos, elas precisam revender a participação que detêm nas empresas investidas. Essa etapa chama-se saída (exit) e é fundamental para esse ramo de negócios (GOMPERS; LERNER, 1999).

Durante o período 1999-2004, analisado por Ribeiro (2005), ocorreram 162 saídas. A maioria (32\%) das saídas foi realizada por meio de venda estratégica (trade sale) da participação do fundo de VC/PE para um grupo industrial interessado em integrar a empresa vertical ou horizontalmente.
Com as mudanças de percepção dos investidores a respeito das empresas de internet, muitos gestores viram que parcela significativa de seu portfólio não iria atingir o retorno esperado. Assim, outra maneira de saída bastante utilizada no período $(27,8 \%$ do total) foi a liquidação total dos ativos (write-off/down), que significa a descontinuação das operações da empresa investida. Esse mecanismo ocorreu substancialmente em 2001 e 2002 (foram 35 nestes anos, do total de 45). Esses números refletem o que seria uma espécie de limpeza do portfólio, efetuada pelas organizações de VC/PE. Correspondem a empresas que não apresentavam mais as perspectivas de crescimento que justificaram o investimento inicial (RIBEIRO, 2005).

O mecanismo de recompra da participação do fundo de VC/PE, por parte do empreendedor - buyback - apareceu em terceiro lugar, representando $19,7 \%$ das saídas do período. Evidências empíricas mostram que muitas vezes as operações de buyback são meros substitutos de uma liquidação (RIBEIRO, 2005).

Em contraste com o período 2001-2003, o ano de 2004 foi extremamente positivo para o setor de VC/PE. Em 2004 ocorreu pela primeira vez a saída por meio de IPO. Cinco empresas que realizaram IPO na BOVESPA, em 2004, receberam aporte de capital de nove fundos de VC/PE (RIBEIRO, 2005). As nove saídas por meio de IPO representam 23,7\% das saídas ocorridas em 2004.

Embora tímida, a estratégia de saída por meio de IPO representa uma alternativa importante para o setor brasileiro de VC/PE, que voltou a ser repetida em 2005, 2006 e 2007, o que indica que foi completado o primeiro ciclo de investimentos do setor. Das 72 ofertas públicas iniciais (IPOs) que ocorreram na BOVESPA, de 2004 até julho de 2007, 28 foram de empresas que receberam aporte de capital do tipo VC/PE. Esses dados mostram como o setor de VC/PE tem influenciado o mercado acionário brasileiro.

Quanto às perspectivas de continuidade de atuação no setor de VC/PE, dentre as 65 organizações de VC/PE, apenas sete empresas revelaram a intenção de abandonar o setor e uma apresentou indecisão. O baixo índice de abandono (12\%) indica que o setor está se consolidando e mostra que os gestores com experiência no mercado identificaram condições necessárias para continuar investindo em VC/PE no Brasil (RIBEIRO, 2005).

\section{Marco legal e iniciativas institucionais no setor brasileiro de VC/PE}

$\mathrm{O}$ estabelecimento de um mercado de VC/PE depende da conformação de um ambiente econômico, institucional e legal adequado à atuação dos atores (NASCIMENTO, 2006). As relações estabelecidas entre os investidores, companhias de VC/PE, fundos de VC/PE e empresas 
investidas estão sujeitas ao arcabouço legal de cada país e ao mesmo tempo sustentam-se nesse arcabouço. Regras legais bem estabelecidas definem o funcionamento pleno do setor de VC/PE (KORTUM; LERNER, 2000).

As 65 organizações de VC/PE, atuantes no Brasil ao final de 2004, administravam 90 veículos de investimento, constituídos de várias formas, como mostra a Tabela 4.

A estrutura mais freqüente era a de fundos constituídos sob instruções da Comissão de Valores Mobiliários (CVM). Entre estes estavam 21 Fundos Mútuos de Investimentos em Empresas Emergentes (FMIEE), dez Fundos de Investimentos em Participações (FIP) e seis fundos constituídos sob a Instrução CVM 409. Dos fundos CVM, dois eram listados em bolsa de valores (RIBEIRO, 2005).

A segunda estrutura mais utilizada para constituição dos fundos de VC/PE no Brasil, a limited partnership (LP), é a que congregava maior parte do capital comprometido do setor ( $68 \%$ do total).

Os veículos estruturados sob a forma de holdings eram muito comuns até 1994. De 1994 até 1998, as LPs passaram a representar mais da metade dos fundos de VC/PE lançados anualmente. A partir de 1999, os fundos criados sob as instruções CVM passaram a ganhar importância, com destaque para os FIPs, que correspondem a mais da metade dos fundos lançados a partir de 2003. A tendência é que os FIPs ocupem o lugar das LPs como estrutura de preferência para os investimentos em VC/PE no Brasil (RIBEIRO, 2005).

A limited partnership (LP) não está prevista na legislação brasileira. Uma das principais vantagens da LP é sua flexibilidade tributária. Os ganhos são tributados somente no momento do resgate das cotas e cada investidor paga a alíquota em que está sujeito. Além disso, o investidor (limited partner) não assume responsabilidade legal sobre passivos que venham a ultrapassar o capital investido (CARVALHO et al., 2006).

Tabela 4. Estrutura legal dos fundos de VC/PE. Fonte: Ribeiro (2005).

\begin{tabular}{lcc}
\hline \multicolumn{1}{c}{ Estrutura legal } & $\begin{array}{c}\mathbf{N}^{\circ} \text { de fundos } \\
\text { de VC/PE }\end{array}$ & $\begin{array}{c}\text { Comprometimentos } \\
\text { (bilhões de US\$) }\end{array}$ \\
\hline $\begin{array}{l}\text { Limited partnership } \\
\text { Empresas de participação }\end{array}$ & $29(32,2 \%)$ & $3,45(68,2 \%)$ \\
(holding) & & $0,52(9,4 \%)$ \\
CVM 391 e 406 (FIP) & $10(11,1 \%)$ & $0,41(8,2 \%)$ \\
CVM 409 & $6(6,7 \%)$ & $0,2(3,9 \%)$ \\
CVM 209 (FMIEE) & $21(23,3 \%)$ & $0,17(3,3 \%)$ \\
Alocação orçamentária & $2(2,2 \%)$ & $0,31(6,1 \%)$ \\
de grupo empresarial & & \\
(corporate venture) & & \\
Outras estruturas & $2(2,2 \%)$ & $0,01(0,1 \%)$ \\
Total & $90(100 \%)$ & $5,07(100 \%)$ \\
\hline
\end{tabular}

Pela legislação brasileira, quando os investidores se utilizam de uma holding estão sujeitos às leis aplicáveis às sociedades anônimas. Assim, inexiste a segregação entre investidor e gestor de fundo com papel nitidamente fiduciário. Com relação aos tributos, os impostos sobre os ganhos de capital são recolhidos pela própria holding, o que significa que todos os investidores pagam a mesma alíquota que a empresa (34\%). Além disso, a holding não tem duração limitada e só pode receber investimentos estrangeiros se ela for de capital aberto (CARVALHO et al., 2006).

A CVM instituiu estruturas que se aproximam das LPs. Dessa forma surgiram a Instrução CVM 209, de 1994, que instituiu os FMIEEs e a Instrução CVM 391, de 2003, que instituiu os FIPs. Esses fundos têm como vantagens a possibilidade de receber investimentos estrangeiros sem que sejam de capital aberto, tributação diferenciada aos seus cotistas, duração limitada, processo simplificado de liquidação financeira dos investimentos e, no caso de reinvestimento, os impostos são postergados. A principal desvantagem é a obrigatoriedade de transparência na gestão, o que é muitas vezes indesejável, como por exemplo, o fornecimento de informações consideradas estratégicas pelo gestor (CARVALHO et al., 2006).

Em relação aos FMIEE, os FIPs removem a limitação de tamanho das empresas investidas, que podem também ser de capital aberto. A liberdade contratual entre as partes (gestores e cotistas) e o registro automático do fundo na CVM conferem inegável flexibilidade aos FIPs. Como os FIPs são constituídos sob a Instrução CVM 391, de 2003, é de se destacar que essa estrutura tenha atraído número significante de fundos e de capital em tão pouco tempo (CARVALHO et al., 2006).

Também podem ser instituídos veículos de investimento sob a Instrução CVM 409. Dentre as diversas modalidades de fundos com designação padronizada pela CVM 409 estão os fundos de ações, usados como veículos de VC/PE. Estes fundos devem manter $67 \%$ de sua carteira em títulos negociados em bolsa de valores ou mercado de balcão organizado (especialmente adequados para investimentos do tipo PIPE ou mezanino). As decisões de investimento seguem as diretrizes estabelecidas pela assembléia de cotistas, cabendo ao gestor a execução dos negócios com valores mobiliários em nome do fundo (CARVALHO et al., 2006).

Além de legislação apropriada, o bom funcionamento do setor de VC/PE necessita de políticas públicas que subsidiem e estimulem seu funcionamento, assim como organizações de apoio, que incentivem seu desenvolvimento, como entidades de classe, órgãos governamentais e sem fins lucrativos, dentre outras iniciativas (KORTUM; LERNER, 2000). 
As primeiras ações institucionais de destaque, que buscam impulsionar o setor brasileiro de $\mathrm{VC} / \mathrm{PE}$, são muito recentes.

Somente em 2000, foi criada a Associação Brasileira de private equity e venture capital (ABVCAP), originalmente denominada Associação Brasileira de Capital de Risco.

$\mathrm{O}$ apoio governamental às atividades de $\mathrm{P} \& \mathrm{D}$ das empresas e à inovação tem contemplado também expandir o aporte de capital do tipo VC/PE a pequenas e médias empresas de base tecnológica, seja mediante alocação de recursos públicos, seja por meio de iniciativas destinadas a promover maior aproximação entre essas empresas e investidores potenciais (GUIMARÃES, 2006).

A ação governamental nessa direção tem sido implementada basicamente no âmbito do Projeto Inovar, lançado em maio de 2000, pela FINEP - Financiadora de Estudos e Projetos. O Projeto Inovar é uma ação estratégica da FINEP, que tem por objetivo promover o desenvolvimento das pequenas e médias empresas de base tecnológica brasileiras, por meio da criação de instrumentos para o seu financiamento, especialmente o capital de risco. Assim, o Projeto Inovar visa construir um ambiente institucional que favoreça o desenvolvimento da atividade de VC/PE no Brasil. O Projeto Inovar contempla o Fórum Brasil Capital de Risco (venture forum FINEP), o seed Fórum, a Incubadora de Fundos Inovar, o Fórum Brasil de Inovação, o Portal Capital de Risco Brasil, a Rede Inovar de Prospecção e Desenvolvimento de Negócios e o desenvolvimento de programas de capacitação e treinamento de agentes de Capital de Risco (FINEP, 2007).

O venture forum FINEP é uma agenda permanente de rodada de negócios, em que potenciais empreendedores têm a oportunidade de apresentar seus planos de negócios a uma platéia de investidores selecionados - notadamente gestores de fundos de VC/PE, bancos de investimento e fundos de pensão (GUIMARÃES, 2006). Trata-se de um modelo consagrado nos Estados Unidos, que contribuiu significativamente para o desenvolvimento do mercado de capital de risco norte-americano (FINEP, 2007).

De 2000 até 2007, ocorreram 15 rodadas do venture forum FINEP. O que diferencia o venture forum FINEP de iniciativas similares em outros países é o processo de preparação das empresas, o que contribui para aumentar as chances das empresas participantes receberem aporte de capital. Assim, a empresa recebe apoio para elaboração e aperfeiçoamento do plano de negócios, assessoria na estruturação do negócio em seus aspectos organizacional, estratégico, financeiro e jurídico, bem como suporte na apresentação aos investidores (FINEP, 2007).

Em 2007, a FINEP iniciou o seed forum, voltado para empreendimentos menores. A meta do seed forum FINEP é apoiar empreendimentos promissores que estão em fase inicial de implementação e organização de operações, muitas vezes ainda dentro de incubadoras e universidades. Nesse estágio, o capital semente é o recurso que vai ajudar na capacitação gerencial e financeira, ação fundamental para o crescimento e consolidação das empresas (FINEP, 2007).

O programa Fórum Brasil de Inovação busca a aproximação entre empresas emergentes de base tecnológica e investidores potenciais. Essa aproximação ocorre por meio dos programas Fórum Brasil de Capital de Risco e Incubadora de Fundos Inovar (GUIMAR ÃES, 2006).

O programa Incubadora de Fundos Inovar tem por objetivo apoiar as empresas nascentes e emergentes de base tecnológica por meio da criação de fundos de venture capital. Nesse sentido, propõe-se a apoiar, com aporte de recursos, a criação de novos fundos voltados para tais empresas e atrair para a atividade os investidores institucionais, especialmente os fundos de pensão (GUIMARÃES, 2006).

A Incubadora de Fundos Inovar realizou, entre 2001 e 2006, sete chamadas públicas para apresentação de propostas de capitalização de fundos de venture capital. Juntos, os 13 fundos aprovados por intermédio da Incubadora realizaram investimentos em 47 empresas inovadoras, possuem cerca de R $\$ 600$ milhões comprometidos, sendo que destes, a FINEP, sozinha, comprometeu cerca de R\$ 100 milhões (1/6 do capital). Além disso, dos 14 fundos de VC ativos na Comissão de Valores Mobiliários, lançados entre 2000 e 2006, mais de $50 \%$ foram viabilizados por meio da Incubadora Inovar. O papel da ação de investimentos da FINEP, na qual se insere a Incubadora Inovar, é justamente atrair investidores para o mercado e reuni-los na seleção e análise de novos gestores e administradores de recursos (FINEP, 2007).

O BNDES anunciou a decisão de realizar investimentos de R \$ 260 milhões na criação de sete fundos de $\mathrm{VC}$, voltados para pequenas e médias empresas de base tecnológica, e de dois fundos de PE, aos quais destinará R\$ 260 milhões, estimando que estes fundos possam alavancar investimentos totais de R \$ 1 bilhão. O BNDES, via BNDESPar, terá participação de até $30 \%$ do patrimônio comprometido dos fundos de VC e de até $20 \%$ do patrimônio dos fundos de PE (GUIMARÃES, 2006).

\section{Considerações finais}

$\mathrm{O}$ setor brasileiro de VC/PE é recente e pequeno. Está distante da exuberância dos EUA, que foi de US\$ 1 bilhão, em 1985, para US\$ 400 bilhões, em 2007. Entretanto, já é possível constatar a sua importância para o desenvolvimento econômico do país e apresenta boas perspectivas de crescimento.

O grande ciclo de desenvolvimento do setor brasileiro de VC/PE iniciou-se após a estabilização monetária, 
tendo seu pico em 2000, impulsionado pelas empresas de internet. O setor está se consolidando, os gestores estão mais experientes após o primeiro ciclo de investimentos e $o$ alto percentual de organizações gestoras com intenção de permanecer no setor mostra que foram identificadas condições necessárias para continuar investindo em $\mathrm{VC} /$ PE no Brasil.

A economia brasileira, que tem apresentado maior robustez, parece não ter sido impactada de forma significativa pela crise no segmento de crédito imobiliário de alto risco dos EUA e pela incerteza quanto à evolução da economia global. O país deverá continuar em sua trajetória de crescimento, sustentado essencialmente pela demanda doméstica. A consolidação de um cenário de estabilidade macroeconômica duradoura contribui para a continuidade do processo de redução progressiva da percepção de risco macroeconômico que vem ocorrendo nos últimos anos. O comportamento dos preços de ativos brasileiros sinaliza a consolidação da confiança dos investidores internacionais na economia brasileira. O espaço para que sejam praticados juros reais menores deverá continuar se consolidando, como consequiência dessa melhora de percepção.

Cenários favoráveis à criação de novos empreendimentos e ao crescimento dos existentes significam maiores oportunidades de investimento para os fundos de $\mathrm{VC} / \mathrm{PE}$.

A queda nas taxas de juros torna as aplicações de renda fixa menos atraentes, o que leva a uma migração dos investimentos para a renda variável. Com isso, grandes investidores, como os fundos de pensão, devem procurar alternativas de investimento como os fundos de VC/PE.

$\mathrm{O}$ aumento da confiança dos investidores internacionais na economia brasileira deve fazer com que mais recursos externos entrem no País, impulsionando, dentre outros setores, o de VC/PE, uma vez que a maioria do capital comprometido no setor brasileiro de $\mathrm{VC} / \mathrm{PE}$ tem origem estrangeira.

A estratégia de saída (desinvestimento) condiciona todo o ciclo de investimento em VC/PE. No Brasil, embora a maioria das saídas tenha ocorrido sob a forma de venda estratégica, o crescente número de saídas por meio de IPO, na BOVESPA, a partir de 2004, mostra que o setor brasileiro de VC/PE já possui condições de causar impacto no mercado de capitais brasileiro. Das 72 empresas que realizaram IPO na BOVESPA, de 2004 até o primeiro semestre de 2007, 39\% receberam aporte de capital do tipo VC/PE e foram responsáveis por $58 \%$ do volume de recursos captado nas aberturas de capital do período.

As saídas por meio de IPO, em geral, são as que possibilitam o alcance de maiores ganhos para o setor de VC/PE. Assim, ao mesmo tempo que este tipo de saída impulsiona o mercado acionário brasileiro, têm-se, com a crescente possibilidade de sua utilização, incentivos ao desenvolvimento do setor brasileiro de VC/PE.

$\mathrm{O}$ setor de $\mathrm{VC} / \mathrm{PE}$ apresenta-se como uma alternativa para o financiamento da inovação tecnológica. O propósito das empresas, ao inovar, é criar ativos escassos e, portanto, que permitam uma elevada valorização do capital investido. Na busca por esses elevados ganhos de capital os fundos de VC/PE dão especial atenção às EBTs.

Além disso, o aporte de capital do tipo VC/PE é um tipo de financiamento mais condizente com os investimentos em inovação tecnológica, que possuem característica de longo prazo e apresentam grande incerteza com relação a seus resultados (quanto será e quando ocorrerá sua geração de caixa), o que não combina com o pagamento periódico de amortização e juros, típicos de financiamentos tradicionais.

Contudo, enquanto na Europa e nos EUA as fases de start-up e capital semente apresentam números mais expressivos, dados do setor brasileiro de VC/PE mostram que os aportes de capital, ao final de 2004, concentravam-se em empresas em estágios mais avançados de desenvolvimento, por apresentarem riscos relativamente menores.

Dessa maneira, o setor público possui uma função importante como investidor em fundos de $\mathrm{VC} / \mathrm{PE}$, não somente no sentido de estimular o desenvolvimento deste setor, mas, principalmente, no aspecto de direcionar os aportes de capital para áreas em que ocorre maior escassez de recursos, como o financiamento de empresas em fase inicial de seu desenvolvimento (capital semente e start-up), sobretudo das EBTs.

Nesse sentido, as iniciativas do BNDES e da FINEP possuem papel fundamental. Assim, os fundos de VC/ $\mathrm{PE}$ consistem em mecanismos pelos quais o governo pode financiar o desenvolvimento de inovações tecnológicas sem ter que arcar integralmente com o montante de recursos aplicados nas empresas. Diferentemente de financiamentos públicos tradicionais, em que o capital (tão escasso) e o risco são integralmente do governo, os fundos de VC/PE permitem que o capital e o risco sejam compartilhados entre o governo e a iniciativa privada.

Outra iniciativa importante para o desenvolvimento do setor de VC/PE é a alteração do marco regulatório. Os FIPs, constituídos sob a Instrução CVM 391, que é de 2003, devem tornar-se em breve a forma preferida de constituição dos fundos de VC/PE no Brasil. A regulamentação dos FIPs parece ser mais adequada às necessidades do setor, já que permite maior flexibilidade e agilidade aos fundos de VC/PE.

Aos empreendedores que almejam obter um aporte de capital do tipo VC/PE é importante salientar que o critério de seleção é rigoroso, não havendo espaço para amadorismos e informalidades. 
Por fim, iniciativas como as de Carvalho; Ribeiro e Furtado (2006), que receberam a denominação de Primeiro Censo Brasileiro sobre private equity e venture capital, são importantes para uma melhor compreensão da dimensão e características do setor brasileiro de VC/
PE. Outras pesquisas sobre o tema são necessárias, principalmente aquelas que permitam analisar a evolução do setor brasileiro de VC/PE em comparação aos outros países e, também, em relação às iniciativas públicas e privadas, necessárias para impulsionar seu desenvolvimento.

\title{
Venture capital and private equity in Brazil: alternative of financing for high technology industries
}

\begin{abstract}
This study analyzes the Brazilian venture capital and private equity industry (VC/PE), its main characteristics and tendencies, as well as its potentiality as a financing alternative for companies in general and mainly for high technology industries. This work also shows the changes in the legislation and the main government initiatives for the development of the VC/PE industry in Brazil.
\end{abstract}

Keywords: Venture capital. Private equity. Finance. Technology.

\section{Referências bibliográficas}

BACEN. Banco Central do Brasil. Ata da 130 ${ }^{\mathrm{a}}$ Reunião do Comitê de Política Monetária (COPOM). Disponível em: $<$ http://www.bcb.gov.br/?COPOM130>. Acesso em: 25 out. 2007

BECK, T.; LEVINE, R. External dependence and industry growth: does financial structure matter? World Bank Policy Research Working Paper, Washington, D.C. 2002. Disponível em: <http://siteresources.worldbank.org/DEC/ Resources/16166_external_dependence.pdf>. Acesso em: 12 jul 2006.

BOTTAZZI, L.; DA RIN, M.; HELLMAN, T. The changing face of the european venture capital industry: facts and analysis. Journal of private equity, New York, v. 8, n. 1, spring, 2004.

CARVAlHO, A. G.; RIBEIRO, L. L.; FURTADO, C. V. A indústria de Private Equity e Venture Capital: primeiro censo brasileiro. São Paulo: Saraiva, 2006. 135 p.

CGEE. Centro de Gestão e Estudos Estratégicos. Capital de risco e desenvolvimento tecnológico no Brasil: experiência recente e perspectivas. 2003a. Disponível em: <http://www. venturecapital.gov.br>. Acesso em 14 set. 2006.

Capital de risco no Brasil: marco legal e experiência internacional. 2003b. Disponível em: http:<//www. venturecapital.gov.br>. Acesso em: 14 set. 2006.

CHRISTENSEN, J.L. The role of finance in National System Innovation. In: LUNDVALL, B. (Org.) National system of innovation: toward a theory of innovation and interactive learning. New York: Pinter, 1992. 342 p.

DE NEGRI, J. A.; SALERNO, M. S.; CASTRO, A. B. Inovações, padrões tecnológicos e desempenho das firmas industriais brasileiras. In: DE NEGRI, J. A.; SALERNO, M. S. (Org.). Inovações, padrões tecnológicos e desempenho das firmas industriais brasileiras. Brasília: IPEA, 2005. 716 p.

DOSI, G. Sources, procedures and microeconomics effects of innovation. Journal of economic literature, Pittsburgh, PA, v. 26, n. 3, p. 1120-1171, sept., 1988.
FAGERBERG, J. Technology and international differences in growth rates. Journal of economic literature, Pittsburgh, PA, v. 32, n 3, p. 1147-1175, sept. 1994.

FINEP. Financiadora de Estudos e Projetos. Portal Capital de Risco Brasil. Disponível em: < http://www.venturecapital.gov. br>. Acesso em: 10 out. 2007.

FREEMAN, C. The economics of industrial innovation. Londres: Pinter Publishers, 1982. 409 p.

GALANTE, S. P.; GLEBA, D. T. An overview of the venture capital industry and emerging changes. The Private Equity Analyst newsletter. Wellesley, USA: Galante Editor \& Publisher, 1996.

GANZI, J. et al. Leverage for the Environment: A Guide to the Private Financial Services Industry. Washington: World Resources Institute, 1998. Disponível em: <http://www.wri. org>. Acesso em: 15 set. 2006.

GOMPERS, P. A., Optimal Investment, Monitoring, and the Staging of Venture Capital. The Journal of Finance, Malden, MA. The American Finance Association. v. 50, n. 5, p. 14611489, dec. 1995.

GOMPERS, P. A.; LERNER, J. What drives venture capital fundraising? National bureau of economic research. NBER working paper series, n.6906, 1999. Disponível em:< http:// www.nber.org/papers/>. Acesso em 14/04/2006.

GONÇALVES, E. Financiamento de empresas de base tecnológica: algumas evidências da experiência brasileira. Revista Econômica do Nordeste, Fortaleza. Banco do Nordeste, v. 33, n. 1, p. 49-70, 2002.

GUIMARÃES, E. A. Políticas de inovação: financiamento e incentivos. Texto para discussão n. 1212. Brasília: IPEA, 2006. $65 \mathrm{p}$.

HEIJS, J. Política tecnológica e innovacion: evaluación de la financiación pública de I+D em España. Madrid: Consejo Econômico y Social, 2001. 267 p. 
KORTUM, S.; LERNER, J. Assessing the contribution of venture capital to innovation. The RAND journal of economics, Santa Monica, CA, v. 31, n. 4, p. 674-692, 2000.

Does venture capital spur innovation? National bureau of economic research. NBER working paper series, Cambridge, n. 6846, 1998. Disponível em:< http://www.nber.org/papers/>. Acesso em: 14 abr. 2006.

MEGGINSON, W. Toward a global model of venture capital? Journal of applied corporate finance, Malden, MA, Blackwell, v. 16, n. 1, p. 8-26, 2004.

NASCIMENTO,L.A.ATrajetória RecentedaInstitucionalização do Venture Capital no Brasil: Implicações para o Futuro. Campinas, 2006. Dissertação - (Mestrado em Política Científica e Tecnológica). UNICAMP.

NASCIMENTO, M. L. Financiamento: importância para o crescimento econômico, condicionantes e análise do caso brasileiro. São Paulo, 2004. 60p. Dissertação - (Mestrado em Economia). FEA/USP.

NELSON, R.; WINTER, S. An evolutionary theory of economic change. Cambridge: Cambridge U. Press, 1982. 437 p.
NVCA. National Venture Capital Association. Year in review: 2004-2005. Arlington, VA: NVCA, 2005.

OECD. ORGANISATION FOR ECONOMIC CO-OPERATION AND DEVELOPMENT. Developments in venture capital and private equity since the and of tech bubble. Paris: OECD, 2005.

PAVANI, C. Condições para a estruturação de uma indústria de capital de risco no Brasil. Rio de Janeiro, 2002. Dissertação (Mestrado em Engenharia de Produção). COPPE/UFRJ.

RIBEIRO, L.L. O modelo brasileiro de private equity e venture capital. São Paulo, 2005. 137 p. Dissertação - (Mestrado em Economia). FEA/USP.

SAHLMAN, W. The structure and governance of venture capital organizations. Journal of financial economics, North-Holland, v. 27, n. 2, p.473-521, oct. 1990.

SEBRAE. Serviço de Apoio às Micro e Pequenas Empresas. MPEs de Base Tecnológica: conceituação, formas de financiamento e análise de casos brasileiros. Relatório de Pesquisa. Julho. 2001.

VALOR FINANCEIRO. Private equity e venture capital. Especial. Ano 6. v. 7. set., 2007.

\section{Sobre os autores}

\section{Jorge Luís Faria Meirelles}

Universidade Federal de São Carlos - UFSCar, Campus de Sorocaba Rodovia João Leme dos Santos, km 110, CEP 18052-780, Sorocaba, SP, Brasil, e-mail: jorgeluis@ufscar.br

\section{Tabajara Pimenta Júnior}

Departamento de Administração - FEA-RP, Universidade de São Paulo - USP,

Av. dos Bandeirantes, 3900, CEP 14049-000, Ribeirão Preto, SP, Brasil,

e-mail: taba.jr@terra.com.br

\section{Daisy Aparecida do Nascimento Rebelatto}

Departamento de Engenharia de Produção - EESC, Universidade de São Paulo - USP,

Av. Trabalhador Sãocarlense, 400, CEP 13560-970, São Carlos, SP, Brasil,

e-mail: daisy@sc.usp.br 
